\title{
RETORNO (VALOR) DE INVESTIMENTO EM INFORMAÇÃO: DECIFRA-ME OU TE DEVORO
}

\author{
RETORNO (VALOR) DE INVERSIÓN EN INFORMACIÓN: \\ DECIFRAME O TE DEVORO
}

\begin{abstract}
Patricia Zeni Marchiori - pzeni@ufpr.br
Doutora em Comunicação - Ciência da Informação (ECA/USP). Professor Adjunto do Departamento de Ciência e Gestão da Informação da Universidade Federal do Paraná (UFPR).
\end{abstract}

\begin{abstract}
Resumo
O artigo discute a aplicação de levantamentos de retorno/valor de investimento (ROI/VOI) para produtos/serviços de informação em diferentes ambientes, abordando o comportamento de uso da informação pelo usuário final, as possíveis métricas e suas inerentes complexidades. Identifica e analisa os parâmetros de custo e benefícios sociais advindos das ações informativas sob a ótica do fluxo dadoinformação-conhecimento e propõe quatro enfoques estratégicos para a elaboração do $\mathrm{ROI}$ /VOI em informação. Adiciona um segundo nível de reflexão ao destacar o reconhecimento do "custo total da falha" como sendo um estímulo a práticas de gestão da informação e documentação conectadas direta e indiretamente ao ROI/VOI.
\end{abstract}

\section{Palavras-Chave}

Gestão da Informação; Retorno de Investimento; Custo Total da Falha; Infospend; Valor de Investimento. 


\section{A INFORMAÇÃO COMO MERCADORIA: O NOTÁVEL CICLO ESCASSEZ- ABUNDÂNCIA-ESCASSEZ}

A peculiaridade de um recurso como a informação revela-se nas condições que favorecem e estimulam sua abundância, ao mesmo tempo em que não são poucos os esforços para torná-la artificialmente escassa sob a alegação de agregar-lhe valor. A discussão sobre a recuperação de custos de produtos e serviços de informação iniciou-se em 1980 como parte de um movimento global para elevar a informação à categoria de commodity passível de compra, venda e troca como qualquer outro recurso tangível. Porém, distintamente das demais "mercadorias" esta, em particular, tem a vantagem de ser retida em sua origem, de ser adicionada a diferentes estágios da cadeia de produção de outros recursos físicos, de ser manipulada pela tecnologia para diferentes propósitos, e ter diferentes significados para variados tipos de consumidores (BRINDLEY, 1993). Os processos relativos à noção de "valor agregado" à informação apresentados à época pelo autor, eram:

a) Aumento na acessibilidade: facilidade e rapidez na busca em bases de dados (comparadas com a contrapartida manual), acompanhada de igual rapidez e facilidade na localização e recuperação de documentos disponíveis remotamente; b) Aglomeração: acesso a diferentes bases de dados e informações por uma interface única;

c) Arquitetura/estrutura da informação: diferentes níveis de armazenagem, manipulação por software e acesso a variados tipos de informação (texto, dados numéricos, gráficos, imagens);

d) Processamento de transações de negócios: informação e tecnologia permitindo ações integradas e em tempo real, tais como reservas em companhias aéreas e aplicações financeiras, por exemplo;

e) Reutilização da informação: reaproveitamento da informação coletada originalmente para um propósito definido em outro(s) contexto(s).

Sob esta ótica e em uma economia, então mais dependente do movimento físico de "bens" informativos, termos como "indústria cultural" e "indústria da informação" eram utilizados para definir e justificar, grosso modo, os altos custos (explícitos ou subsidiados) envolvidos no ciclo de criação e distribuição de recursos de informação. Da mesma forma, esforço, tempo e habilidades especiais comprometidos na localização, avaliação, solicitação e recebimento de informação contribuíam para reforçar uma noção geral de escassez. Ainda as- 
sim, Shapiro (1999) alertava para o fato de que os custos de "primeira cópia" de um bem informativo se tornavam triviais a partir da segunda cópia em diante. Além disto, ao se assumir por "informação" qualquer coisa que possa ser digitalizada, esta situação se potencializaria devido à duplicação não controlada e de baixo custo. Conseqüentemente, a cobrança para a recuperação de custos na produção se constituiria em um problema fundamental da economia da informação.

Como previsto, a sociedade passou a investir de forma significativa em uma infraestrutura de redes de acesso rápido e ilimitado como plataforma para serviços e espaços virtuais que estimulam a colaboração e diluem as tradicionais fronteiras entre a tomada de decisão empresarial, o entretenimento e a comunicação científica. Este ambiente de todos, por todos e para todos caracteriza-se por exaltar critérios individuais de qualidade de informação com base em comentários, votações e classificações/medidas de audiência (ratings). Tal cenário abre um amplo leque de discussões que vão desde os direitos de patentes e acesso exclusivo a determinados conteúdos, ao extremo oposto da proliferação de discursos de auto-proclamados especialistas (individuais ou reunidos em coletividades) que disputam a atenção de uma audiência nem sempre fiel. Se, de um lado, a escassez é provocada artificialmente para criar/manter um poder de autoridade e justificar custos e práticas de preços, por outro, a situação de "fartura" de recursos informativos exige uma luta permanente para reduzir a característica entrópica da informação em ciclos cada vez mais curtos de tempo entre a necessidade, acesso e uso.

Quer gratuita, quer adquirida via "transferência por compra" de um livro ou um DVD ou pelo pagamento por uso privativo de um arquivo de música, a informação pode ser vista como bem de experiência (SHAPIRO, 1999). Os consumidores precisam acessar parte ou o todo de um produto ou serviço de informação a fim de comprovar as condições de exatidão, oportunidade e relevância - ou outros critérios que compõem sua cadeia de valor pessoal para se disporem a aceitar o uso e/ou efetuar algum pagamento. Contribuiriam para um reforço desta "análise de risco" a marca do fornecedor e, mais especificamente, a reputação de seus criadores.

Anderson (2008), Jensen (2007) e Kelly (2008) apontam para o que vem sendo chamado de freeconomics, que se caracteriza pela superabundância de recursos e vetores de informação com base nas poderosas tecnologias da web. Kelly (2008) explica que a abundância de cópias de informação na rede rapidamente se transforma o recurso e seu conteúdo em algo banal. As possíveis métricas neste contexto corresponderiam a um "tipo" de 
atenção do consumidor ao que lhe é apresentado e, nesta economia de trocas, quaisquer produtos e serviços - incluídos os de informação - são oferecidos como retorno à cessão de dados e metadados sobre o seu uso. Tais dados seriam mais valiosos do que o item gratuito em si e, sob esta mesma lógica, não é necessário cobrar diretamente do consumidor final, mas sim daqueles que se beneficiam da atenção gerada ou estimulada por um determinado ponto de acesso na rede, como por exemplo, o fluxo de clicagem de links de anúncios patrocinados no Google Adsen$s e^{1}$. Portanto, o "valor agregado" preconizado por Brindley (1993) se configuraria em uma aposta de futuro, onde um conjunto de tera/petabytes de "comportamento de uso" poderá resultar no oferecimento de novos produtos e serviços. Estas constatações e justificativas explicitam uma contradição e divergência nos conceitos e objetivos de se aplicar a mensuração de investimentos, pois muitas vezes os gastos de hoje só trarão resultados amanhã.

Pensar em retorno de investimento (ROI) normalmente envolve uma conotação monetária que, historicamente, se refere a um conjunto de métricas capturadas a partir de componentes tangíveis de um ne-

\footnotetext{
${ }^{1} \mathrm{O}$ Google AdSense é um serviço que permite aos editores veicularem anúncios Google nas páginas de conteúdo de seus sítios web de forma a obter alguma vantagem financeira (adaptado de: http://www.google.com.br/support/adsense/bin/static .py?page $=$ common.html).
}

gócio, produto ou serviço, tal como o volume de recursos financeiros (ou o tempo) economizado em algum processo. Pode ainda ser definido como cálculo contábil do tempo necessário para a amortização de um investimento e o ponto em que este passa a gerar lucros. Um enfoque clássico do ROI para a informação é o termo infospend apresentado por Garratt e Du Toit (2003), conceituado pelos autores como sendo a relação entre o custo e o efetivo uso do produto/serviço de informação e a possibilidade de geração de lucro em algum ponto do processo. Os autores sugerem alguns indicadores de desempenho, tais como o custo hora/homem; o custo dos recursos de informação (impressa e eletrônica) coletados interna e externamente; o tempo de processamento/preparo do produto/serviço de informação; e o custo dos direitos autorais. Na mesma linha de raciocínio, as métricas de resultados em projetos digitais (BERWANGER, 2007) - chamadas genericamente de web analytics tais como click-throughs ${ }^{2}$, visualizações de páginas, número de visitantes, visitantes únicos (entre outras contagens), demonstram estatisticamente os hábitos de navegação de um determinado segmento de usuários, permitindo análises que - potencialmente - auxiliam a justificar os investimentos on-line e alavancar o ativo digital

\footnotetext{
${ }^{2}$ Também conhecido como ad click ou transfer e ocorre quando um visitante de um sítio web clica um banner de anúncio e é transferido para o sítio web do anunciante.
} 
das empresas. Porém, em todas as situações, o que está em jogo é, a partir de tais métricas e outros estudos qualitativos complementares, determinar se o produto/serviço atrai a atenção, desperta a confiança e lealdade, mantém o interesse ao longo do tempo e estimula a construção de vínculos pessoais e profissionais. Estes são os complexos componentes intangiveis da organização que só recentemente foram reconhecidos. Em 2001, o Gartner Group definiu como "valor do investimento" (VOI) as medidas relacionadas com o benefício decorrente do emprego de recursos que poderiam demonstrar a eficiência das "ações" de informação na produtividade e competitividade (HURLEY, apud NORRIS, 2003). Portanto, o VOI está relacionado com a cultura das organizações e dos indivíduos dentro e fora delas, sendo um complemento do ROI no que tange à interdependência, nem sempre em equilíbrio, dos investimentos em tecnologia e aqueles voltados para recursos humanos.

A tensa relação entre a recuperação/geração de lucros e o impacto individual, institucional e social decorrente do uso da informação como ativo estratégico, acomoda diferentes interpretações a partir dos objetivos particulares de cada organização e de sua orientação para os negócios. Assim como (quase) tudo o que diz respeito à gestão da informação acarreta abordagens sócio-técnicas/tecnológicas, este assunto não é exceção. A contribuição deste artigo é, então, propor - de forma não exaustiva - algumas questões de fundo da temática do retorno/valor de investimento em informação, a saber: os ambientes de aplicação do ROINOI, a inseparabilidade da mensuração e impactos e sua possível visualização no fluxo dado-informaçãoconhecimento, e o efeito do chamado "custo total da falha" nas discussões de $\mathrm{ROI} / \mathrm{VOI}$ em organizações.

Importa esclarecer que, mesmo apresentando-se alguns itens de "custo", o texto não pretende focalizar o tema sob o ponto de vista financeiro-contábil. Tal escopo será explorado em próxima oportunidade, reconhecendo-se de antemão que um conjunto de fórmulas para o cálculo de métricas e a criação/discussão de modelos teria como ponto de partida inicial o benchmarking de estudos e práticas nas áreas de recursos humanos, marketing e análise do valor de marcas.

\section{PARÂMETROS PARA O ROI/VOI: LU- CROS, CONTEÚDO, ATENÇÃO E BE- NEFÍCIOS SOCIAIS}

A arena informacional contemporânea é caracterizada por um mercado cada vez mais amplo, descentralizado e competitivo; por pressões para a transparência administrativo-contábil; e por restrições orçamentárias. Inicialmente, é possível falar de três espaços para a análise do conceito de 
ROI/NOI: o ambiente das organizações com fins lucrativos, o ambiente das organizações filantrópicas/sem fins lucrativos, e o ambiente razoavelmente híbrido representado pelas atividades acadêmicas e de pesquisa.

Organizações orientadas para a geração de lucros, tais como as empresas de capital privado, calculam o ROI considerando, de maneira geral, a participação no mercado e aumento direto em vendas, mensurando os custos dos ativos, a manutenção de dados históricos para análise de tendências, entre outros aspectos. Neste ambiente, conforme já explicitado por Brindley (1993), a informação é adicionada aos diferentes estágios da cadeia de produção de outros recursos físicos, acompanhada de crescentes investimentos em Intranets, portais corporativos e sítios web que são, notoriamente, produtos/serviços intensivos em informação. Além disto, a análise de risco para investimentos em gestão de informação e gestão documental em corporações deve levar em conta os procedimentos e obrigatoriedades definidas por legislações, normas e procedimentos voltados para amenizar e evitar o chamado "custo total da falha" (a ser explorado posteriormente no texto).

Para Griffiths et al. (2004), a aplicação de medidas de custo/benefícioefetividade, impacto e retorno de investimento em organizações sem fins lucrati- vos, tais como bibliotecas, museus, parques e instituições educacionais, esbarram em dificuldades devido ao conjunto de produtos/serviços não taxados, que diferem entre si quanto à oferta, ao tipo de uso em cada ciclo de demanda, e em relação a cada usuário em particular. Contudo, esclarecem os autores, a redução de orçamentos e as demandas pela transparência na aplicação de recursos públicos exigem suporte contábil que comprovem as vantagens de se investir em uma determinada instituição. Resultados obtidos em recente estudo demonstraram que o apoio financeiro para as aproximadamente nove mil bibliotecas públicas dos EUA não está apenas baseado em um "vago sentimento de altruísmo", mas em um retorno econômico real para indivíduos, famílias e comunidade em geral (ONLINE COMPUTER LIBRARY CENTER, 2008). Anteriormente, a pesquisa de Griffiths et al. (2004), voltada para as bibliotecas públicas na Flórida/EUA utilizou dados demográficos, econômicos e sociais para comprovar o retorno de investimento como um conjunto de benefícios diretos, na forma de melhoria nas capacidades e oportunidades para a população; na redução de conseqüências indesejáveis (desemprego e taxas de encarceramento, por exemplo), entre demais indicadores. Outras organizações, especialmente do terceiro setor, têm utilizado uma abordagem inovadora apoiada nas discussões sobre o $\mathrm{VOI}$, intitulada social return on investment (SROI). Este 
tipo de ROI insere os stakeholders (parceiros, clientes, funcionários, acionistas e o próprio governo) no centro do processo de mensuração, traduzindo os resultados sociais e ambientais em valores monetários tangíveis.

Citadas no parágrafo anterior, as organizações voltadas para ensino e pesquisa também tem sido alvo de restrições econômicas que aceleram estudos de viabilidade e de auto-sustentabilidade, pautados pela busca por novas fontes de investimento. Assim como nos demais espaços, o uso maciço de tecnologias de informação e comunicação cria expectativas de redução de custos e aumento de produtividade a partir da transformação de processos e práticas voltadas para novos níveis de desempenho (NORRIS, 2003). Goldstein e Katz (2005) apresentam a expressão academic analytics como um possível guardachuva para as análises dos negócios da instituição, abrangendo termos considerados mais "empresariais" (inteligência competitiva) ou aqueles restritos ao uso de tecnologias (data mining). Com base nas academic analytics, uma instituição de ensino pode identificar os resultados que deseja alcançar - diminuir a evasão de alunos, sustentar argumentos para a atração de investimentos, entre outros - cruzando dados históricos já existentes e, a partir daí, definir indicadores e elaborar planos de treinamento e envolvimento de pessoal que venham a modificar algumas práticas e atitudes, por exemplo. Concomitantemente, as métricas de produtividade de pesquisadores, grupos de pesquisa e das próprias instituições enfrentarão modificações substanciais à medida que há mais e mais material disponível on-line e em repositórios de acesso aberto. Novas possibilidades de mensuração baseadas em avaliações abertas e citações em rede colocarão em cheque o controverso modelo vigente baseado em índices de impacto obedientes à autoridade de editoras e dos periódicos "de elite".

Comum aos três espaços citados, o ciclo da informação pré-web 2.0 - explicitado como um grupo de processos linear de produção/coleta, armazenamento/tratamento, busca/acesso e distribuição/uso e avaliação - tem migrado para um modelo que agrega aspectos dinâmicos, tais como - mas não exclusivamente - o monitoramento e compartilhamento descentralizados; a sincronia e publicação individual intensiva, acompanhada de imediata disseminação; as aferições de mérito abertas; e a necessidade de proteção da integridade de versões (Figura 1). 


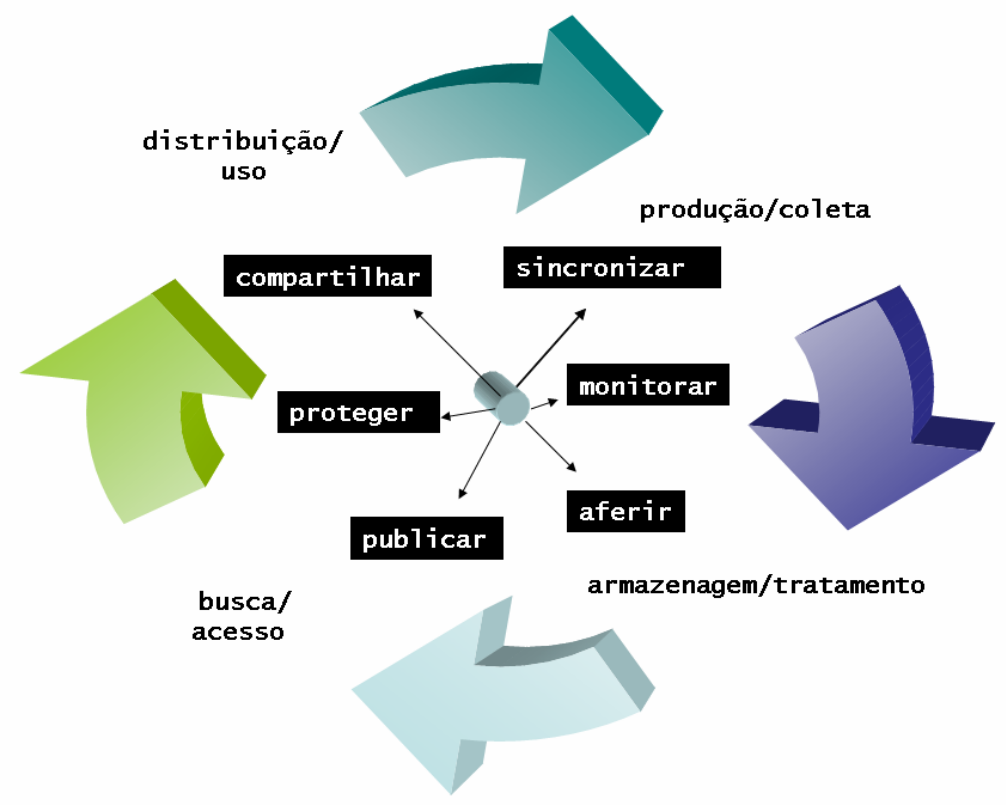

Figura 1 - Ciclo da informação e as dinâmicas de participação

Desta forma, tanto um portal corporativo empresarial ou um sítio web criado para a venda de produtos on-line, como um ambiente colaborativo em rede em uma universidade, ou ainda o acesso remoto a serviços e produtos de informação de uma biblioteca, apresentam um objetivo em comum, ou seja, viabilizar o acesso ao conhecimento a potenciais interessados. $O$ estímulo à participação e funcionalidades que permitem a cada indivíduo opinar, modificar, remixar, votar e recomendar o que está disponível em rede confirma que os esforços em determinar o retorno de investimento em informação se assemelham a acertar um "alvo em movimento" (PINHEIRO, 2005). De levantamentos puramente contábeis para propostas que envolvem o conjunto total de benefícios individuais e sociais o cálculo do ROI/VOI tem sofrido constantes alterações.

Neste sentido, um exercício de extrapolação para o cálculo do ROI/VOI em informação poderia ser enunciado da seguinte maneira: é possível visualizar - com base no modelo dado(D), informação(I) e conhecimento(K) - os diferentes graus de envolvimento do usuário de produtos/serviços de informação? Caso positivo, quais seriam os níveis de complexidade envolvidos?

\section{DOS DADOS ÀS INFORMAÇÕES E (UM POUCO) DE CONHECIMENTO: CUSTOS E INDICADORES}

O oferecimento de qualquer produto/serviço de informação em rede - como, por exemplo, um sítio web - gera métricas tidas como "comuns", pois estão relaciona- 
das diretamente com os custos de infraestrutura que permitem armazenar, buscar, recuperar, copiar, filtrar, interferir, manipular, agregar, transmitir, receber e enviar informação. Tais custos podem ser divididos em:

a) Custos iniciais: compra de hardware (computadores/periféricos), estrutura física para acesso à rede, software (aquisição de licenças), produtos de informação associados (assinaturas de bases de dados, pacotes de informação sobre produtos tangíveis, por exemplo), trabalho (implantação, treinamentos), e espaço físico (metros quadrados, reformas e similares).

b) Custos recorrentes: manutenção do hardware, renovação de licenças e assinaturas, treinamento contínuo, salários da equipe responsável, e consultorias.

Neste ponto da análise, pode-se dizer que há um ROI direto relacionado com os custos iniciais e decorrentes dos ativos tangíveis, entendidos como fatos/dados diretamente coletados de documentos de compra/venda de equipamento e contratos de consultoria e do pessoal encarregado.

A partir daí, o valor agregado potencial deste investimento seria traduzido em alguns benefícios, tais como: melhorar a acessibilidade à informação (rapidez); oferecer uma estrutura/arquitetura da informação visando facilitar e tornar a navegação e a recuperação consistente; atuar como pla- taforma de aglomeração de conteúdos; oferecer informação crítica e condições de compartilhamento e colaboração; permitir atividades de síntese, solução ou recomendação; definir o design de perfil e personalização; permitir a integração com outras aplicações; favorecer processos que se desdobram a partir de um conteúdo disponibilizado (externalidade/exterioridade); e monitorar a taxa de reutilização de informação (BRINDLEY, 1993; HARRIS, 1999 apud CLOETE; SNYMAN, 2003).

Estes "saltos de qualidade" apoiados na infra-estrutura podem ser mensurados e, dependendo da estratégia do responsável, as métricas decorrentes revelariam três outras possibilidades de definição do ROI/VOI em informação:

a) ROI/VOI inferencial: gerado a partir do monitoramento de uso - derivado das web analytics ${ }^{3}$ - e de algumas ações, nem sempre consideradas "simpáticas", tais como a exigência de preenchimento de dados pessoais e de preferências para o acesso a promoções ou produtos/serviços. Acompanhar a fidelidade, o tempo despendido na navegação e identificar graus de exterioridade, permite inferir o engajamento e envolvimento do cliente e configurar seu perfil. Este conjunto de métricas revela um

\footnotetext{
${ }^{3}$ Web Analytics is the measurement, collection, analysis and reporting of Internet data for the purposes of understanding and optimizing Web usage (http://www.webanalyticsassociation.org/en/cms/?30 6).
} 
primeiro nível de impacto e um benefício/valor agregado potencial;

b) ROI/VOI espontâneo: interações mais conscientes e voluntárias do usuário como, por exemplo, a ação de postar um comentário em um blog ou inscrever-se como colaborador na Wikipedia, aparecerá como menção numérica no conjunto de dados de tráfico do produto/serviço de informação. Ainda que tais dados possam novamente - levar a inferências de que houve um esforço de análise e síntese e, conseqüentemente, um grau de participação, torna-se necessário qualificá-la quanto ao conteúdo expressado nesta interação (se corroborativo, negador, propositivo ou complementar, por exemplo). Tais métricas explicitariam um segundo nível de impacto com base em informações em um nível superior de elaboração cognitiva, representando um benefício/valor agregado real para o conjunto de usuários estudado. A qualidade de tal informação dependeria de amostras corretas, provenientes de uma base de usuários representativa e íntegra.

c) ROI/VOI estimulado: seguindo-se o mesmo raciocínio anterior, usuários "participativos" seriam localizados via dados gerados pelas estatísticas coletadas no espaço virtual que acomoda o produto/serviço de informação. O número de acessos, de postagens e de ações identificadas como "colaborativas", isto é, o preenchimento voluntário de enquetes, vota- ções espontâneas, indicação de recursos para sua rede de contatos, entre outros critérios, seriam tomados como critérios para a identificação de um usuário com postura ativa. Partindo-se do pressuposto que usuários fiéis e participativos normalmente são influentes e tendem a ter uma posição crítica em relação ao que consomem na rede, estes seriam candidatos naturais para participarem de dinâmicas qualitativas, tais como grupos de foco e entrevistas por telefone. Neste nível, o que está em jogo é o processo de análise e construção de um conhecimento consensual (ou não) sobre o produto/serviço com forte apoio em uma riqueza de interpretações quanto aos impactos reais do produto/serviço.

Resumidamente, a inter-relação entre dado(D), informação(I) e conhecimento(K) e a evolução das métricas de ativos para métricas de impacto pode ser vista na Figura 2. 


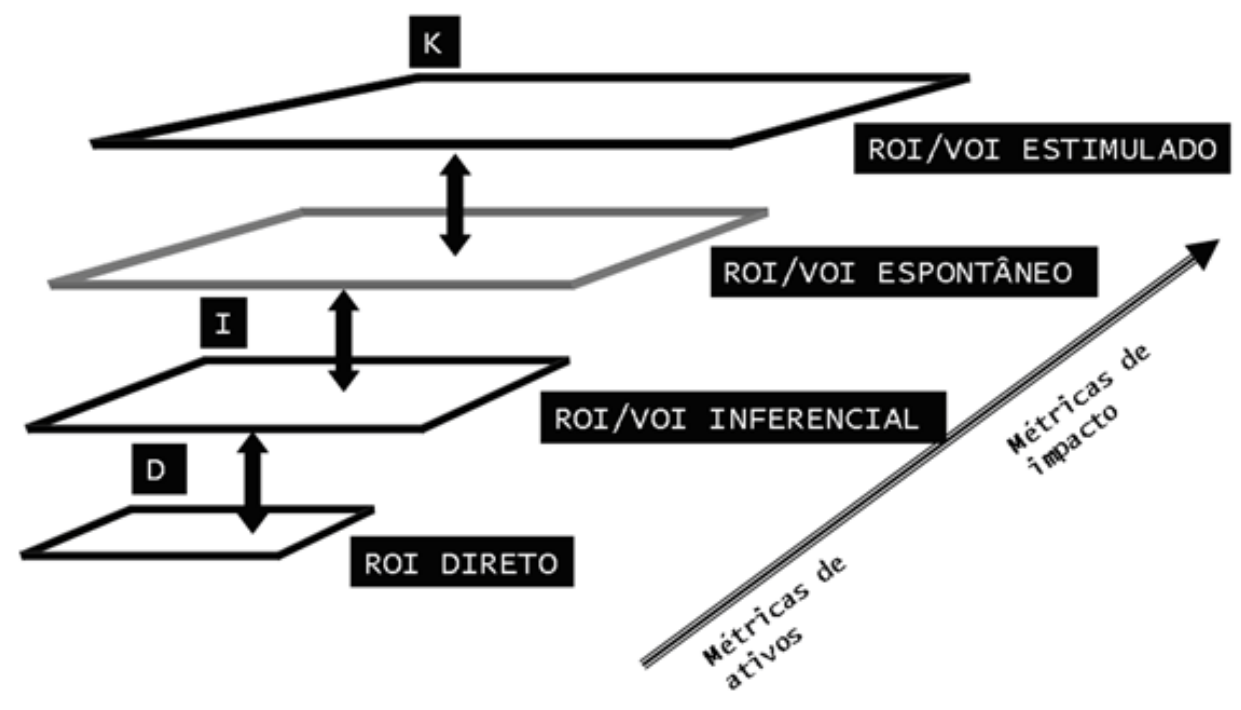

Figura 2 - Dados, informação e conhecimento como a base para o ROI/VOI em informação.

Cabe destacar que a elaboração de tais métricas não é isenta de investimentos financeiros que tendem a crescer em relação direta com o ROI/VOI pretendido devido, em grande parte, às técnicas de coleta e análise. Justificar "os custos para identificar custos" não é tarefa simples. Todavia, as conseqüências legais e financeiras de falhas no gerenciamento da informação e documentos, especialmente em organizações corporativas, têm influenciado no entendimento e na aceitação dos custos das ferramentas, levantamentos e outras atividades que englobam o cálculo do ROI/VOI.

\section{AS CONSEQÜÊNCIAS DO "CUSTO TOTAL DA FALHA" E SEUS EFEITOS NO ROI/VOI}

O fato de se ter ou não métricas para calcular o retorno do investimento em informação não deveria influenciar a decisão entre investir ou não em sistemas, produtos e serviços desta natureza. Falhas em encontrar a informação relevante para se defender de uma ação de natureza jurídica ou como resposta a um processo de auditoria têm conseqüências concretas que vão desde multas substanciais e custos imprevistos que estouram o orçamento, passando pelo encarceramento de executivos até, em casos extremos, a falência de uma organização. Um exemplo da importância crescente de uma correta gestão de informações financeiras é a Lei SarbanesOxley, instituída nos Estados Unidos em 2002, com o objetivo de proteger os interesses de investidores e consumidores de produtos fabricados por empresas com ações na Bolsa de Nova York. O texto da lei, monitorada pela Security and Exchange Commission (SEC), inspirou-se na série de 
escândalos financeiros que abalaram a credibilidade da economia americana nos últimos anos. Seu texto, entre outros aspectos, define mecanismos de controle quanto à destruição, alteração ou falsificação de registros; controle dos períodos de arquivamento e o fluxo de informação (PIZZANI, [2005?]).

Particularmente no ambiente organizacional, em que unidades de informação estão sendo fechadas ou reduzidas, os funcionários e colaboradores são encorajados a adquirir, controlar e gerenciar, eles mesmos, os recursos que avaliam como sendo importantes para a criação e o desenvolvimento de conhecimento. Conseqüentemente, algumas das unidades de negócio podem não encontrar a informação que necessitam, enquanto outras partem para o tudo ou nada, comprando o que estiver disponível, na esperança que o uso futuro justifique os custos envolvidos (HENCZEL, 2000). Ambas as estratégias acarretam falhas, inconsistências e duplicidade de recursos informativos, agravadas pela implementação de Intranets, sistemas de gerenciamento de conteúdo e conhecimento, portais corporativos e soluções de workflow, em que se verifica mais uma vez o paradoxo da solução (ampliação do acesso à informação) como causa de um novo problema (seu aumento exponencial).

O nível de comprometimento da organização com a informação necessária para seus propósitos identifica-se, via de regra, com a atividade de "auditoria da informação". Não é objetivo deste artigo explorar tal temática, mas os princípios gerais da auditoria da informação (disponibilidade, tempo de recuperação, quantidade de informação solicitada e taxa de êxito na localização (GARRATT; DU TOIT, 2003), são áreas de intersecção entre o custo total da falha e o retorno de investimento.

SKJEKKELAND (2005) exemplifica que, em uma demanda simples de localização/recuperação de informação que possa ser relevante como evidência para cumprimento de qualquer regulamentação vigente, os custos totais da falha incluem:

a) Custos de busca e recuperação;

b) Diminuição na produtividade;

c) Perda de tempo dos empregados;

d) Perda potencial de reputação (valor da marca);

e) Perdas imediatas ou futuras nos resultados dos negócios;

f) Custos de software, hardware (e consultoria) necessários para acessar ou "desenterrar" os registros;

g) Declínio na moral e produtividade dos empregados;

h) Penalidades por atrasos ou destruição de evidências. 
A preocupação com estes impactos manifesta-se especialmente no ambiente corporativo. Estudo realizado em 1999, junto às mil maiores empresas norte americanas por ordem de rentabilidade, Fortune 1000, permitiu construir estimativas de perdas acarretadas pela ineficiência da gestão de informações. Cálculos baseados em salários anuais dos "trabalhadores de conhecimento" em relação às horas trabaIhadas por semana/ano, das quais se subtraíram médias de desperdício de tempo na busca de informação, de re-trabalho/recriação de informação já existente, mas perdida na organização, produziram cifras e cenários que, potencialmente, estimulariam as empresas a investirem em "governança corporativa" (FELDMAN; SHERMAN, 2001). Um efeito imediato da aplicação de recursos financeiros em práticas eficientes de gestão da informação e documentação seria o de se ter respostas imediatas à demandas - nem sempre íntegras - de consumidores, empregados, fornecedores - ou mesmo do próprio Estado (SKJEKKELAND, 2005).

\section{A FUNCIONALIDADE DO ROI/NOI: UM ELEFANTE NA LOJA DE LOUÇAS}

Sob uma visão mais pragmática, o resultado final de um estudo de ROI/VOI é, geralmente, um conjunto de estatísticas acompanhadas de porcentagens e gráficos provindos de mensurações e/ou de resul- tados de estudos/observações qualitativas. Espera-se que tais "figuras" explicitem o lucro (a ser) obtido ou apóiem argumentos para a negociação de novos aportes financeiros e/ou manutenção dos já existentes. Porém, indicadores e métricas são relativos a partir do reconhecimento de que os sistemas de informação nunca serão completos, as interfaces perfeitamente adequadas, a arquitetura de informação consistente, e que os usuários nunca serão homogêneos.

Dificuldades adicionais surgem ao se verificar que os treinamentos podem ter falhas - especialmente quando o usuário não pertence à organização que disponibiliza os produtos/serviços de informação - e quando os interessados têm dificuldades em traduzir suas necessidades frente à interface do sistema que apresenta o(s) recurso(s).

Ainda que seja possível visualizar o fluxo dado-informação-conhecimento no processo de coleta de elementos para o cálculo do ROI/VOI em informação, esta constatação reforça a complexidade das ações que compõem tal levantamento.

Um primeiro nível de complexidade surge da necessidade de se decidir o que medir, ou seja, os indicadores e variáveis envolvidos e os pontos de observação/fonte(s) de dados para tais mensurações. Deste, depreende-se o segundo nível de complexidade. Isto é, o porquê medir. 
Qual a justificativa do processo de mensuração? o lucro? a redução/aumento de desempenho? a (capciosa) satisfação? outra(s) razão(ões)?

Portanto, assim como em outras áreas, traduzir o ROI/VOI a uma contagem simples de itens recuperados é tão simplista quanto inocente. A interpretação dos resultados de um estudo neste particular ainda deverá responder a questão que acomete qualquer processo métrico quanto aos parâmetros de comparação: o grau de retorno/valor do investimento em informação é positivo/negativo/inalterado em relação à organização ela mesma em outros períodos, ou em relação a terceiros? Há um parâmetro considerado ótimo? Quando o resultado pode ser considerado "ruim", "bom" ou de "excelência"?

Deve-se considerar, adicionalmente, que as características sinergéticas, difusivas e partilháveis da informação, espelhadas nos produtos e serviços derivados, revelam que não há uma solução única para atender todos os fins. Um produto/serviço de informação, desde que criado com um mínimo de atenção as necessidades de seu público-alvo preferencial poderá provar seu mérito em algum momento. Porém, caso seja comparado com outros "de melhor desempenho" e apresente um baixo ROI/VOI, isto será motivo suficiente para decretar sua extinção?
Além disto, e como se não bastassem os caveats envolvidos na proposta estratégica de um estudo de ROI/VOI, deve se levar em conta que "boas" métricas devem ser claras quanto aos propósitos e procedimentos; precisas e transparentes; geradoras de dados idôneos e válidos; significativas para todos os envolvidos; reproduzíveis; simples de aplicar; e, sobretudo, econômicas.

\section{REFERÊNCIAS}

ANDERSON, Chris. Free! why $\$ 0.00$ is the future of business. Wired Magazine, San

Francisco, v. 16, n. 3, 2 feb. 2008. Disponível em:

$<$ http://www.wired.com/techbiz/it/magazine/ 16-03/ff free>. Acesso em: 11 out. 2008.

BERWANGER, Sthefan. Quer ser profissional de web analytics? Veja como. Webinsider, Rio de Janeiro, 8 dez. 2007. Disponível em:

$<$ http://webinsider.uol.com.br/index.php/20 07/12/08/quer-ser-profissional-de-webanalytics-veja-como/>. Acesso em: 15 set. 2008

BRINDLEY, Lynne Janie. Information service and information product pricing. Aslib Proceedings, London, v. 45, n. 11/12, p. 297-305, nov./dez. 1993.

CLOETE, Marian; SNYMAN, Retha. The enterprise portal: is it knowledge management? Aslib Proceedings, London, v. 55, n. 4, p. 234-242, 2003. Disponível em: $<$ http://www.emeraldinsight.com/10.1108/0 0012530310486593>. Acesso em: 22 mar. 2006.

FELDMAN Susan; SHERMAN, Chris. The high cost of not finding information: an IDC white paper. Framingham: IDC, jul. 2001. Disponível em: 
$<$ http://www.viapoint.com/doc/IDC\%20on\% 20The $\% 20$ High $\% 20$ Cost $\% 20$ Of $\% 20$ Not $\% 2$ 0Finding\%20Information.pdf $>$. Acesso em: 15 ago. 2008.

GARRATT, Olwyn; DU TOIT, Adeline. Accountability and demonstration of the value of information services in South African law firms. Aslib Proceedings, London, v. $55 \mathrm{n}$. 3, p.130-137, 2003. Disponível em: $<$ http://www.emeraldinsight.com/10.1108/0 $0012530310472624>$. Acesso em: 24 nov. 2005.

GOLDSTEIN, Philip J; KATZ, Richard J. Academic analytics: the uses of management information and technology in higher education, EDUCAUSE Review, Boulder, v. 42, n. 4, jul./aug. 2005. Disponível em: $<$ http://net.educause.edu/ir/library/pdf/ers05 08/rs/ers0508w.pdf>. Acesso em: 12 out. 2008.

GRIFFITHS, José-Marie et al. Taxpayer return on investment in Florida Public Libraries: summary report. set. 2004. Disponível em:

$<$ http://dlis.dos.state.fl.us/bld/roi/pdfs/ROIS ummaryReport.pdf>. Acesso em: 19 set. 2008.

HENCZEL, Susan. The information audit as a first step towards effective knowledge management. INSPEL: international journal of special libraries, Munich, v. 34, n. 3/4, p. 210-226, 2000. Disponível em: $<$ http://www.ifla.org/VII/d2/inspel/003hesu.pdf >. Acesso em: 18 set. 2008.

JENSEN, Michael. The new metrics of scholarly authority. The Chronicle Review, San Francisco, v. 53, n. 41, p. B6, 15 Jun. 2007. Disponível em: <http://chronicle.com/free/v53/i41/41b0060 1.htm>. Acesso em: 21 set. 2008.

KELLY, Kevin. Everything, too cheaply metered. The Technium, 2008. Disponivel em: $<$ http://www.kk.org/thetechnium/archives/20 08/09/everything too.php>. Acesso em: 21 set. 2008.
NORRIS, Donald M. Value on investment in higher education. ECAR Research Bulletin, Boulder, v. 18, n. 2, sep. 2003. Disponível em: $<$ http://net.educause.edu/ir/library/pdf/ERB 0318.pdf>. Acesso em: 1 jul. 2008.

ONLINE COMPUTER LIBRARY CENTER. From awareness to funding: a study of library support in America. Dublin: OCLC, 2008. Disponível em:

$<$ http://www.oclc.org/reports/funding/default .htm>. Acesso em: 11 out. 2008.

PINHEIRO, José Maurício Santos. O retorno de investimento em projetos de redes. 18 fev. 2005. Disponível em:

$<$ http://www.projetoderedes.com.br/artigos/ artigo roi.php>. Acesso em: 20 aug. 2008.

PIZZANI, Luiz. Sarbanes-Oxley: Você está preparado? Dados \& Negócios - Online, ed. 10. [2005?] Disponível em:

$<$ http://www.dadosenegocios.com.br/vocee stapreparado.html>. Acesso em: 14 ago. 2008.

SHAPIRO, Carl; VARIAN, Hal R. A economia da informação: como os princípios econômicos se aplicam à era da Internet. Rio de Janeiro: Campus, 1999.

SKJEKKELAND, Atle. Information management compliance: a 2005 United Kingdom Industry Study. Silver Spring: Industry Watch, 2005. Disponível em: <http://www.aiimhost.com/AllM News/UK I ndustry Watch for Compliance.pdf >. Acesso em: jul. 2008.

\section{Title}

Return (value) on Investment in Information: a devouring sphinx

\section{Abstract \\ It approaches the return/value of investment on information products and services (ROI/VOI) in different environments, and the data collection that unveils the end user information behavior.}


The measures and their complexities are discussed as well as the costs and social benefits derived from information actions, which could be aligned with the data-information-knowledge flow. It proposes four strategic views to be applied to the ROI/VOI in information, adding the "total cost of failure" as a second level of concern, bearing in mind the advantages of applying information and documentation management tools and techniques to the ROI/ VOI scrutiny.

\section{Keywords}

Information Management; Return on Investment, Total Cost of Failure; Infospend; Value Investment.

\section{Titulo}

Retorno (valor) de inversión en información: deciframe o te devoro

\section{Resumen}

El artículo discute la aplicación de investigaciones del retorno/valor de inversión (ROI/VOI) para productos/servicios de información en distintos ambientes. Aborda las posibles mensuraciones y sus complejidades y el comportamiento de uso de información. Identifica e analiza los costos y los beneficios sociales como consecuencias de acciones informativas bajo el modelo de flujo dato-informaciónconocimiento. Además, propone cuatro ejes estratégicos hacia la elaboracion de un ROI/VOI en información y añade un segundo nivel de discusión al acercar el reconhecimiento de los "costos totales de la falla" hacia las practicas de gestión de información y documentación y su conexión con el ROI/VOI.

\section{Palabras-Clave}

Gestión de Información; Retorno de la Inversión, Costo Total de fracaso; Infospend; Valor de Inversiones

Recebido em: 08.10.2008

Aceito em 14.11.2008 